\title{
FORMAÇÃO DOS TRABALHADORES E LUTA DE CLASSES
}

\author{
Virgínia Fontes $\left({ }^{*}\right)$
}

\section{Resumo}

Tece considerações sobre processos de formação e de educação para a classe trabalhadora em sociedades capitalistas, voltados para a inserção no mercado de trabalho (formação para o capital), deseducadores e des-formadores. Destaca as formas de ingerência empresarial direta e indireta na educação pública brasileira. Apresenta a Educação do Campo como experiência original, capaz de apontar possibilidades para a educação-formação da classe trabalhadora, com elaboração, formulação e execução paralelas à organização da própria classe e estreita conexão entre ensino e pesquisa.

Palavras chave: Educação - Formação - Classe Trabalhadora

\section{Resumen}

Reflexion sobre la formación y la educación para la clase obrera en las sociedades capitalistas, para ajustarla al mercado de trabajo (formación para el capital), deseducadoras y des-formadoras. Destaca las formas de interferencia burguesa directa e indirecta en la educación pública brasileña. Presenta la Educación del Campo como experiencia original, capaz de señalar posibilidades para la educación y la formación de la clase obrera, con formulación y ejecución paralelas a la organización misma de la clase y estrecha relación entre la enseñanza y la investigación.

Palabras Clave: Educación - Formación - Clase obrera

Professora da Pós-Graduação em História da UFF e da Escola Politécnica de Saúde Joaquim Venâncio-Fiocruz. Professora da Escola Nacional Florestan Fernandes-MST. Conferência proferida dia 28/09/2016 no III Intercrítica: Intercâmbio Nacional dos Núcleos de Pesquisa em Trabalho e Educação, realizado na UTFPR, Curitiba-PR. Foram realizados apenas pequenos ajustes ao texto original.

TrabalhoNecessario - www.uff.br/trabalhonecessario; Ano 14, № 25/2016 
Em primeiro lugar, quero agradecer o convite para estar com vocês aqui em Curitiba, na Conferência de Abertura deste III Intercrítica, e o carinho da insistência para que eu conseguisse vir, especialmente de Célia Vendramini e de Marileia. Não sou uma pesquisadora da pedagogia, mas uma historiadora, militante da educação e da formação da classe trabalhadora, e vocês não encontrarão nessa intervenção as devidas citações (apenas algumas, especialmente relevantes para exemplificar certas passagens). Além disso, certamente encontrarão imprecisões conceituais. Certamente todos encontrarão no caderno que está sendo preparado com as demais intervenções maiores precisões sobre categorias caras à área da Pedagogia.

Organizei essa intervenção em quatro pontos, procurando contextualizar alguns dos desafios dramáticos para a classe trabalhadora decorrentes das características atuais da expansão do capitalismo.

1. uma breve definição - incompleta, para fins dessa argumentação - de educação formal e da escolarização capitalista apontando elementos que se encontram mesclados e entremeados na vida social concreta;

2. uma breve definição de formação sob o capitalismo e das contradições que a envolvem;

3. algumas experiências contra-hegêmonicas;

4. uma rápida análise dos desafios históricos para uma formação da classe trabalhadora nas condições da massificação expandida da educação escolar, lembrando a importância do controle direto pela classe trabalhadora da educação (nada de mera participação!) - como uma reivindicação fundamental;

\section{1) Separação metodológica do inseparável - instituições educativas formais e formação social.}

A educação nas sociedades capitalistas é apresentada como limitada à educação formal, letramento, acesso à cultura, socialização de conhecimentos fundamentais, hierarquizado até o nível da produção científica, neutralizada e isolada das condições sociais que a geram.

No entanto ela responde sempre a dois movimentos contraditórios: de um lado, a formar "trabalhadores" de níveis diversos (do mais simples ao mais complexo) para assegurar o 'desenvolvimento' do país (isto é, a lucratividade do capital). Expressam-se aqui divergências entre empresários que pretendem TrabalhoNecessario - www.uff.br/trabalhonecessario; Ano 14, № 25/2016 
vender educação e os que precisam comprar trabalhadores devidamente formados (RODRIGUES, 2007). De outro lado, a sociedade capitalista é impelida a responder às exigências de massas crescentes de trabalhadores, que aspiram a (e reivindicam) inúmeras saídas pela educação (mesmo se ambivalentes): a) letramento e conhecimento; b) ascensão social; c) sobrevivência (acesso a emprego ou a empregabilidade, isto é, a arte de se virar sozinho, sem contrato e sobreviver); d) cidadania, ou o acesso aos direitos; e, finalmente, e) aspiram a igualdade de condições. Como se depreende, em sociedades de classe a educação formal é sempre atravessada por contradições que ela não pode resolver no próprio ambiente escolar, que a constituem e ultrapassam, tanto no âmbito dos dominantes quanto dos dominados.

Em função da escala das lutas populares, das tensões entre as classes dominantes nacionais e mesmo das posições relativas das classes dominantes no cenário internacional (imperialismo), desenvolveram-se em muitos países escolas públicas de tipo universal, desde a pré-escola até a universidade (e as pósgraduações), que tendem a se apresentar como se fossem voltadas apenas para uma "educação" pura, "descarnada" das contradições sociais. Esse não é um processo homogêneo e não ocorreu de maneira idêntica nos diferentes países, embora haja uma tendência comum à massificação da escolarização.

Vale lembrar que o fato de haver escolarização pública em grande escala em sociedades capitalistas não isenta as escolas das contradições (como fartamente demonstrado por Pierre Bourdieu). Ao contrário, sua universalização e seu aparente caráter público somente se mantém onde, quando e enquanto as tensões e lutas sociais sejam incorporadas nas escolas, nos programas, nos currículos e prosseguem, fora da escola, como espaço de luta constante. Se as classes dominadas não se organizam, se suas lutas não avançam substantivamente, a tendência é que as escolas se convertam em espaço de sua domesticação, ainda que através de enorme estardalhaço midiático que encobre o recuo das posições das classes subalternas. Podemos citar alguns exemplos díspares, como o avanço do racismo carreado sob a proibição do véu islâmico nas escolas francesas, proibição defendida em nome da neutralidade republicana. A luta pela igualdade social se inverte: se despe de seu conteúdo concreto e assume o véu (um símbolo) como se fosse a expressão da desigualdade... Em outro exemplo, há alguns anos vem ocorrendo enorme difusão midiática da TrabalhoNecessario - www.uff.br/trabalhonecessario; Ano 14, № 25/2016 
indisciplina nas escolas, em diferentes países. Novamente é silenciado o crescimento das desigualdades sociais e a piora das condições de trabalho dos educadores, focalizando exaustivamente apenas atos 'indisciplinados'. Os dois exemplos mostram o crescimento de exigências retrógradas de imposição de autoridade e de disciplinamento, apresentados (e naturalizados) como a tarefa das escolas. Na mesma direção atua a medicalização da vida social, com a criação de diagnósticos controversos - como o Transtorno do Déficit de Atenção e Hiperatividade-TDAH - para comportamentos infantis ou juvenis "irrequietos" ou "rebeldes", seguidos de subsequente difusão de medicamentos para tratar de supostas "doenças", que podem silenciar precocemente as inquietações sociais e juvenis. As conquistas sociais da classe trabalhadora no interior da educação escolar são esvaziadas de seu sentido original, permanecendo como conchas vazias, desprovidas do impulso concreto que animaram as reivindicações e organizações de trabalhadores. O mesmo pode vir a ocorrer com uma das mais importantes conquistas dos movimentos antiracistas, a introdução de cotas. A acomodação e o silenciamento resultantes de pequena conquista - pequena, pois as proporções das cotas são mínimas frente à massa da população oprimida e discriminada que deveria estar em todos os níveis escolares - não leva à sua expansão. Infelizmente, em sociedades capitalistas, o silenciamento dos dominados gera o avanço dos dominantes, levando ao encolhimento das conquistas realizadas.

Mesmo onde houve maior extensão da escola pública, a tendência dominante sob o capitalismo é dirigir e enquadrar o processo de educação (desde um Estado apenas aparentemente "neutro") para a formação adequada ao mercado (de trabalho ou de empregabilidade). Decerto, o Estado capitalista responde a pressões dos dominados, que procuram - e precisam, até mesmo desesperadamente - vender força de trabalho. Isso provoca novas tensões, mesmo quando não são imediatamente contra-hegemônicas: muitas vezes a educação/formação para o mercado não se coaduna com as expectativas dos educandos, muitas vezes infladas pela própria propaganda levada a efeito pelos setores dominantes.

Nas últimas décadas, essas tensões vêm crescendo de vários lados: há mais jovens querendo fazer universidade pública, há mais pressão popular por escolas públicas em escala internacional. Do outro lado, as entidades patronais

TrabalhoNecessario - www.uff.br/trabalhonecessario; Ano 14, № 25/2016 
(patronal aqui está sendo utilizado como sinônimo de empresarial, burguês, capitalista) vêm atuando no sentido de assumir todas as parcelas que possam vir a ser lucrativas na atividade educativa. Em nome da educação para o mercado, da formação da "mão de obra", isto é, educar para a obediência e o conformismo às normas mais ou menos estreitas da subalternidade, cresce o predomínio patronal direto sobre as escolas públicas, assim como aumenta a industrialização da educação. Esse processo tende a ocorrer sob duas modalidades: a privatização direta e a modificação da escola pública.

Não me parece que se trate de acabar com o Estado, nem com os recursos públicos destinados à educação, mas de direcioná-los de forma direta para a valorização apenas do capital (Leher, 2014 e 2015). Pretendem que todo recurso público deva ser direcionado para os 'setores produtivos' (de mais-valor, é claro), isto é, diretamente para entidades empresariais que lucram tanto nos materiais, quanto na venda de programas educacionais, de informatização e, finalmente, na venda da própria concepção curricular e dos processos de avaliação, seja para a escola privatizada, seja para a escola pública. Ao implantar tal predomínio, pretendem ao mesmo tempo lucrar e silenciar as tensões constitutivas da escola, pública ou privada, paga com o salário ou com voucher. Tendem portanto a acirrar as tensões sociais, a curto e médio prazos. ${ }^{1}$

Entrementes, isso significa um extensíssimo processo de deseducação pública generalizada (no público e no privado) ${ }^{2}$. Mais uma vez a formação patronal pragmática tenta domesticar de maneira direta a maior parcela da educação de massas, eliminando qualquer concepção crítica (e até mesmo qualquer voz contraditória), apresentando-se como se resumisse toda a educação ${ }^{3}$. Em alguns países resta ainda alguma preocupação com aspectos

1. Isso pode significar eventuais momentos de maior 'estatização' de parcela da escolarização, desde que as crises sociais (ou o fracasso econômico de indústrias da educação) leve parcelas do empresariado a endossar essa reivindicação, de preferência remunerando novamente o capital, através do mecanismo já clássico da socialização dos prejuízos. Essa foi uma das estratégias capitalistas para a "reforma agrária de mercado", com fartas remunerações a grandes proprietários.

2. Vale conhecer um pouco a situação da educação nos Estados Unidos, através de um depoimento de mãe brasileira que lá vive, sobre as terríveis condições das escolas charter (https://antesqueelescrescam.com/2015/04/13/escola-publica-nos-estados-unidos-e-pior-do-queeu-pensava/), acesso em 20/09/2016 e de artigo científico de FREITAS, 2012.

3. Essa é uma das contradições severas e que merece aprofundamento. A separação entre educação formal e formação é característica do encobrimento das relações capitalistas. Ao investir massivamente na deseducação (formadora para a concorrência no mercado, entretanto) de grandes massas, torna-se mais gritante o papel segregador das classes dominantes.

TrabalhoNecessario - www.uff.br/trabalhonecessario; Ano 14, № 25/2016 
formais do conhecimento, em outros até mesmo isso é desconsiderado. Em todos os casos, a escola massiva (pública e/ou privada) tende a uma atuação formadora para a competição acirrada entre os estudantes, preparando-os para sua vida ulterior de trabalhadores sem direitos, 'responsáveis' por si próprios na competição mercantil, sem igualdade ou equalização de direitos. A socialização para o comportamento da empregabilidade é massiva e extensa; em contrapartida, a socialização dos conhecimentos e da cultura humana sofre processo de retração, promovendo deseducação de grandes massas e apropriação seletiva e restritíssima dos conhecimentos e da 'alta cultura', como a denominou Gramsci. E isso, mesmo que os números absolutos de formados aumente.

No caso brasileiro, que espelha o que vem ocorrendo em diversos países, a situação é mais grave, pois jamais chegamos a sequer uma escola pública de amplo espectro e alcance, nem mesmo uma escolarização geral (pública e/ou privada) capaz de assegurar massivamente a conclusão dos anos de educação obrigatória.

O movimento Escola sem partido é um exemplo gritante de proposta explícita de deseducação, ou de imposição da censura direta sobre o processo de socialização do conhecimento. Mas não é único. O movimento Todos pela Educação, tornado política pública no governo Dilma, é outro exemplo da expropriação da interferência popular na escola pública, assim como do uso direto dos recursos públicos em favor do comando empresarial.

\section{2) Formação de trabalhadores ou adequação para a vida social sob a dominação do capital}

Historicamente, em sociedades capitalistas, a formação para o trabalho ocorre tendencialmente a cargo do patronato (o famoso "mercado"), mesmo nos casos onde ocorreu extensa escolarização pública universalizante. A clássica "dualidade" da escolarização ocorre seja através da imposição direta empresarial, seja através de sua imposição indireta, por processos diversos de hierarquização das instituições e dos estudantes. Essa dualidade geralmente ocorre em escolas massivas e aligeiradas para as grandes massas, contrapostas a uma formação à parte e separada para setores dominantes (como o caso exacerbado da Ivy League, ou dos Master of Business Administration-MBAs multinacionais).

TrabalhoNecessario - www.uff.br/trabalhonecessario; Ano 14, № 25/2016 
Isso é também mais grave quando o patronato - como no caso brasileiro não se responsabiliza nem endossa uma escola pública nem privada à altura de suas próprias exigências e necessidades, nivelando por baixo. $\mathrm{O}$ que pretende? Adequar-se a índices internacionais, de maneira a reduzir a péssima figura da situação da educação brasileira? É o caso gritante do Rio de Janeiro, e da invenção de fórmulas para supostamente 'resolver' o problema da deseducação em grande escala (evasão e iletramento massivos) através da retirada desses estudantes das salas de aula regulares, desaparecendo portanto das estatísticas.

Lucrar a partir das próprias reivindicações de escolarização dos trabalhadores e de seus filhos, através da venda a governos (municipais, estaduais, federal) de programas como o Projeto Autonomia, da Fundação Roberto Marinho? São arranjos de curtíssimo prazo, fugas para a frente de tensões e lutas que reparecerão quase imediatamente.

Nos últimos anos, cresceu a dualização da educação, subalternizada à formação direta para o mercado: Pronatec, Pronacampo, FIES (Prouni) massificam a formação para o capital e se perfilam ao lado do sistema $S$, que se ampliou brutalmente. Esse tipo de formação, aliás, associa para o empresariado o útil (formar mão de obra) ao agradável, pois recebem polpudos recursos públicos sob as mais diversas formas e rubricas, diretos ou indiretos, através de "bolsas" ou vouchers.

A novidade dos últimos tempos é o interesse redobrado pela ocupação direta da Escola Pública pelo empresariado, através de programas privados, "parcerias" e contratação e gestão através de "OS" (Organizações Sociais, isto é, entidades privadas sem fins lucrativos), modelo copiado dos EUA e que se expande no mundo, embora o ritmo da privatização do ensino público seja diferenciado segundo os países. Sem falar do MTPE (Movimento Todos pela Educação) e pela alucinada privatização, não apenas dos recursos públicos, mas do teor e conteúdo dos processos educacionais, o que precariza inclusive a formação para o mercado.

Estamos assistindo à industrialização em larga escala dos processos educativos. Ela será desigual e promoverá simultaneamente novos procedimentos de hierarquização, ao lado de forte deseducação para amplos setores populares. Mas sequer reduz as tensões sociais e, portanto, tende a gerar revoltas crescentes.

TrabalhoNecessario - www.uff.br/trabalhonecessario; Ano 14, № 25/2016 
A situação brasileira é dramática em função da precariedade educacional histórica (deseducação), ao que se acresce uma herança difícil de des-formação da classe trabalhadora nas últimas décadas, por diversos caminhos:

a) através dos componentes objetivos e diretos de dominação do capital sobre o trabalho, aumenta sem cessar desde a restruturação produtiva uma intensa e extensa fragmentação das formas de contratação dos trabalhadores (expropriações secundárias). Ela tem profundos efeitos subjetivos, pois enevoa e obnubila a própria condição de trabalhador para grandes massas que, não obstante, precisam vender força de trabalho para sobreviver. Essa tendência da subcontratação ou do trabalho sem contrato disciplina multiplamente trabalhadores (formação para o capital): pelo despotismo patronal, pela concorrência interna mais acirrada e, finalmente, pelo aumento tanto dos procedimentos de convencimento (que se tornam totalitários) quanto pelo crescimento da violência do Estado, novo déspota direto sobre as relações de trabalho;

b) pelo recuo da formação da classe trabalhadora tanto pelas instâncias sindicais quanto partidárias, especialmente a Central Única dos Trabalhadores-CUT e Partido dos Trabalhadores-PT. Ambos passaram a formar para o enquadramento à sociedade capitalista. De um lado, gestores sindicais e, de outro, requalificação profissional. Em outros termos, partidos de origem popular disseminaram em amplíssima escala a formação de mão de obra, também com recursos públicos (Fundo de Apoio ao Trabalhador-FAT), ao lado das formas tradicionais diretamente empresariais. Isso erigiu uma instância institucional enorme, apartada das condições de luta e cuja existência tem impactos objetivos e subjetivos de longo alcance. Parcela significativa da atuação sindical incorporou os valores do capital;

c) pelo crescimento exponencial do papel privado na formação geral igrejas (escolas dominicais ou outras), mídias proprietárias e redes sociais (círculos tendencialmente fechados, embora extensos).

\section{3) experiências contra-hegemônicas no Brasil}

A mais significativa delas foi a Educação do Campo, empreendida pelo TrabalhoNecessario - www.uff.br/trabalhonecessario; Ano 14, № 25/2016 
Movimento dos Trabalhadores Rurais sem Terra-MST, que precisou enfrentar tanto a inexistência de escola para os trabalhadores rurais, quanto a deseducação (no caso deles, a ausência da educação escolar) quanto a proposta de formação para o mercado destinada aos trabalhadores do campo. Do ponto de vista das práticas educativas e pedagógicas, e da própria elaboração teórica, foi a experiência que mais avançou. Tem claro que não deve dissociar educação e formação e que, portanto, trata-se de educação-formação da classe e para a classe trabalhadora, recusando o papel de formadora de mão de obra.

A Educação do Campo tem o mérito de associar a formulação e sistematização orgânica das exigências de formação às reivindicações de que ela constitua a base da própria educação pública. Em outros termos, teve a ousadia de propor uma educação formulada e conduzida por trabalhadores, mas como dever do Estado. Conseguiu olhar de outra forma a Constituição, integrando-a e superando-a (mas a Constituição ainda existe? ${ }^{4}$ ), Portanto, trata-se de impor desde a classe trabalhadora organizada exigências à formulação, configuração e práticas da educação pública. A experiência do processo (e da luta) mostrou que a Educação do Campo precisa estar permanentemente sob o controle da própria classe trabalhadora organizada, caso contrário a atuação das classes dominantes pode desvirtuá-la por dentro (através da própria burocracia pública) e por fora do Estado (pela intervenção direta empresarial, que planta apoios por dentro do próprio Estado). Não basta assegurar um direito: ele tem de ser exercido permanente e diretamente pelos próprios trabalhadores e jamais delegado a burocratas "peritos" ou convertido em processo rotineiro, banalizado. As tensões evidenciadas a partir da Educação do Campo mostraram como a conexão entre ensino e pesquisa pode assumir papel crucial, auxiliando a compreensão das diversas manobras (algumas evidentes, outras discretas) do empresariado, que tenta subordinar diretamente a educação pública. A reiteração permanente da relação entre o processo educativo e o processo organizativo de diversos setores da classe trabalhadora (e não apenas da parcela de classe atingida diretamente por aquele processo educativo específico) se evidenciou outro ponto nodal, posto repensar permanentemente as conquistas realizadas, tensionando tendências à acomodação ou à adaptação ao molde deseducativo e desformador vigente. Essa 
experiência é fundamental e original, e precisa ser melhor compreendida, divulgada e amplificada resolutamente para outros espaços da classe trabalhadora. Certamente, não se trata de erigir uma experiência - ainda que fundamental - em modelo obrigatório, mas de extrair dessa experiência elementos que nos parecem fundamentais para qualquer educação e formação da classe trabalhadora.

Vale reafirmar algo de extremamente importante nessa formulação: não se trata de reivindicar meramente participação, mas protagonismo de classe, organizadamente. A contribuição do MST não se limitou à educação-formação, mas também à formação-educação, através da Escola Nacional Ffloresta Fernandes.

Há outras iniciativas, que merecem uma pesquisa detalhada de suas propostas, práticas e conquistas concretas. ${ }^{5}$

\section{4) Formação da e para a classe trabalhadora}

Enfim, chegamos no que nos interessa. A formação da classe trabalhadora depende brutalmente da expansão de processos educativos mas vai muito além deles. A escala da deseducação (também em âmbito internacional) e o recuo da dimensão pública tornam nossos desafios muito maiores.

Para a formação da classe, não se trata de adequar para o mercado, nem de formar habilidades, competências ou capacidades específicas para trabalhos previamente determinados. Aqui se trata de uma verdadeira filosofia da existência social, de uma efetiva socialização da capacidade crítica, do enfrentamento às condições de produção da desigualdade social. Aqui, estamos no terreno do enfrentamento de seres sociais concretos com um mundo dominado pela sua redução ao... trabalho, sob quaisquer condições. Aqui, se trata de compreender que a liberdade começa quando as necessidades fundamentais estão satisfeitas. E não ao contrário, como tentam nos impingir na atualidade, onde sugerem que a liberdade se limita a acatar e a obedecer a uma infinita necessidade, sempre

5. Muitos movimentos sociais e sindicatos fizeram ricos experimentos, que precisam ser sistematizados. Como exemplos, o NPC-Núcleo Piratininga de Comunicação (sob a coordenação de Vito e Claudia Giannotti); sindicatos que elaboraram iniciativas educativas e formativas simultaneamente (como o Sintese-Sergipe); tendências políticas que organizam a formação de seus próprios militantes; lutas por uma Universidade Popular (por exemplo, encabeçada pelo Partido Comunista Brasileiro-PCB e outros).

TrabalhoNecessario - www.uff.br/trabalhonecessario; Ano 14, № 25/2016 
crescente. Essa é uma discussão longa, filosófica, que não cabe nesse espaço. Mas que é essencial na formação da classe trabalhadora. Essa não pode ser uma formação que elimine a perspectiva do trabalho necessário, nem que ampute o ser social de suas potenciais atividades criativas - manuais e intelectuais, afetivas e lúdicas. Todos os bens (concretos ou intangíveis, utilitários ou artísticos) resultam da atividade criativa humana, social, ao elaborar e modificar a natureza. A sociedade capitalista tende a tudo reduzir a trabalho vendável, necessidade infinitamente recriada para a grande maioria, destinada a produzir mais-valor incessante para as burguesias.

Essa formação depende da educação, considerada como socialização dos aspectos formais e acesso aos estoques de conhecimento e de experiência disponíveis, mas ambas precisam ser autônomas frente ao Estado e frente ao mercado. Isto é, precisam necessariamente serem anticapitalistas, na sua concepção e atuação prática.

Como não se pode criar um meio não-capitalista em sociedades capitalistas, essa formação precisa concretamente estar na luta, uma vez que os trabalhadores, em condições sempre mais precárias, dispõem de escassos meios, de pouco tempo e têm baixa disponibilidade, que somente poderão ser potencializadas se essa formação fizer parte da própria vida, desde o cotidiano até a dimensão organizativa (que é sempre múltipla). Se ela se converter numa necessidade de outro tipo, que não se limita à subsistência, mas à existência propriamente humana.

Aprendemos socialmente da maneira mais difícil possível que o Estado segue fundamental para o capital e que não é "domesticável". Mesmo quando há conquistas reais, elas devem estar nas mãos da classe trabalhadora organizada e não serem entregues nas mãos de prepostos. Essa é talvez a única experiência que ainda não fizemos, mas que a Educação do Campo do MST mostra (mesmo se com limites e com dificuldades) ser necessária e urgente. 


\section{Referências Bibliográficas}

FREITAS, Luiz Carlos de. Os reformadores empresariais da educação: da desmoralização do magistério à destruição do sistema público de educação. Educação e Sociedade., Campinas, v. 33, n. 119, p. 379-404, abr.-jun. 2012. In: http://www.scielo.br/pdf/es/v33n119/a04v33n119.pdf Acesso: 20/09/2016.

LEHER, Roberto. Movimentos sociais, padrão de acumulação e a crise da Universidade, apresentado na $37^{a}$ Reunião Nacional da ANPEd - GT11 - Política de Educação Superior - 04 a 08 de outubro de 2015, UFSC - Florianópolis. In: http://www.anped.org.br/sites/default/files/trabalho-de-roberto-leher-para-ogt11.pdf. Acesso: 20/09/2016

LEHER, Roberto. Organização, Estratégia política e o Plano Nacional de Educação. Disponível em http://marxismo21.org/wp-content/uploads/2014/08/RLeher-Estrat\%C3\%A9gia-Pol\%C3\%Adtica-e-Plano-Nacional-

Educa\%C3\%A7\%C3\%A3o.pdf. Acesso EM 20/11/2016.

RODRIGUES, José. Os empresários e a educação superior. Campinas: Autores Associados, 2007. 